\title{
Some Remarks on the Forcible Feeding of Insane Patients.*
} By A. R. Tornbulu, M.B.Edin., Medical Superintendent of the Fife and Kinross District Asylum.

In dealing with insane patients the question of forcible feeding comes up for consideration very frequently. It embraces various points of great interest and importance, on each of which much could be said; but in the present paper I wish to confine myself to some short remarks under the following iheads :-(1) The Methods of Forcible Feeding; (2) Feeding by the Esophageal Tube; (3) The Kind of Food used; and (4) A Reference to some Illustrative Cases.

(1.) Methods of Forcible Feeding. - Refusal of food may be due to mere stupidity, or to the restlessness and inattention of maniacal excitement; much more frequently it is seen in cases of melancholia, melancholic stupor, or delusional insanity. In the mildest forms a little persistence and tact will often overcome the difficulty without any actual force being needed. In more marked cases more active persuasion by argument or scolding, the moral effect of threatening to use force or of showing forcible feeding carried out on other patients, and the use of that moderate degree of force which is implied in the attendant or nurse holding the patient's head and gently pressing the spoon into his mouth will be tried, and will be successful in a number of instances. When these means have had a fair trial, and have failed in inducing the patient to take a sufficient amount of food, we have to consider forcible feeding proper, and the various ways in which it can be carried out. These may be arranged in two classes:-(1) The different forms or combinations of spoon, or feeding cup, or funnel, by which food is introduced through the mouth or nose, without the instrument passing further than, or even as far, as the pharynx; and (2) the tube, introduced through either the mouth or the nose, which passes beyond tine pharynx and enters the stomach (csophageal tube). In the former group the food becomes free in the pharynx, above the glottis, and must therefore be introduced intermittently to allow of intervals for breathing. In the pharynx, again, the act of swallowing is not entireiy an involuntary reflex, but is to a certain extent under the control of the patient; and if he refuses to swallow

\footnotetext{
- Read at the Annual Meeting of the Medico-Psychological Association,
} 1895. 
after the food has been poured into the pharynx, there may -and indeed must-be great embarrassment of breathing, with the risk of some particles being drawn into the larynx when an inspiration is at length made. Compression of one or both nostrils will often make the patient swallow in order to clear the mouth and pharynx for respiration; but the risk of some of the food entering the larynx during the patient's struggle is still not definitely eliminated. With the cosophageal tube, on the other hand, respiration can go on freely while it is in position, and the food can be introduced in a continuous or intermittent stream without any interference with the breathing. When the tube has been properly passed there is no possibility of the food entering the larynx, unless regurgitation from the stomach first takes place. The most serious danger in forcible feeding-the one which always looms most largely in the mind of the operator -is that some particles may enter the glottis and set up spasm, with risk of choking, or lead to subsequent lung complications. Hence I would say at once that when a patient resists so persistently as to require forcible feeding proper, it is a good rule always to use the cesophageal tube rather than any apparatus which introduces the food no further than the pharynx. If we watch a nurse trying to feed a resistive patient with the spoon, and see the spluttering of food from the mouth, the choking, the irritation which is often engendered in both patient and nurse by the struggle, and the risk of bruising or other injury, for which it is very hard to hold the nurse responsible, we will probably agree that in such cases the demonstration of force with the spoon should be apparent only, rather than real, and that if the patient does not very speedily become passive the nurse should not persist in her efforts, but should give place to the doctor with the cesophageal tube. With the soft rubber tubes now in use, both for oral and nasal feeding, there is practically no force employed after the mouth has been opened and the tube has reached the lower part of the pharynx. It is simply held there until it engages in the upper end of the csophagus ; its further passage onwards to the stomach is effected entirely by the natural reflex action of the csophageal fibres; and there is thus exceedingly little risk of injury to the cesophagus or stomach, or to the parts in their neighbourhood. The old firm (or hard) form of mouth tube, with wooden lower end, enabled the operator at once to overcome any resistance in the mouth or pharynx, 
and to push the tube onwards along the cosophagus. But this implied a certain amount of actual force, with a corresponding degree of risk of injury (both from the force and from the hardness of the tube) to the cesophagus or other parts, especially if the tube was not directed in the exact line of the alimentary channel. Any such risk is reduced to a mininum, or altogether eliminated, by using the soft rabber tube, with which no pushing force is given ; and as it can be passed in all ordinary cases with as much certainty as the hard tube, though perhaps with less speed, I believe that it should always be employed in preference to the hard tube. I am, of course, assuming that there are no special circumstances in the case, such as the existence of stricture or malignant disease of the cesophagus, which require the usual procedure to be modified to meet them.

(2.) Feeding by the Esophageal Tube.-In proceeding to use the tube the great point aimed at is to secure the patient in such a way as to effectually prevent any risk of injury to him if he struggles during the feeding. For this purpose we may use a special chair, with suitable fastenings or other means of keeping the patient perfectly steady. More commonly the patient is held directly by the attendants or nurses, after having been either laid flat on a mattress on the floor or placed in a sitting up position in bed. The details to be attended to for holding the patient safely in each of these positions are well known, and need not be repeated here. The supine position on the floor is said to give.the greatest amount of control over the patient, and.to have the advantage of less liability to regurgitation of the food. The sitting up position in bed is a nearer approach to the natural position in feeding, and therefore looks less formidable in practice; and if regurgitation does take place there is less risk of the food passing into the larynx than when the patient is lying flat. Probably the choice between the two plans will depend very much on what the operator has accustomed himself and his assistants to. I prefer and use the sitting up position in bed; and if, as may happen, the patient ceases to make any resistance to the feeding process, the transition to the sitting up position in an ordinary chair is more natural and easy. One must, of course, be exceedingly guarded about leaving a patient so far uncontrolled as is implied in letting him sit in an ordinary chair during the feeding; but it is not uncommon to find that patients, after seeing that they can always be overpowered in 
the end, ultimately submit very quietly to the whole process. In the Fife Asylum we have at present three patients, all males, requiring the use of the tube, who are fed in this quiet way in an ordinary chair. One of them opens his mouth for the gag; the other two make a slight show of resistance to the introduction of the gag, but otherwise give no trouble. Possibly the example set by the first of the three may have had some influence in inducing the others to follow suit.

For cesophageal feeding either the nose tube or the mouth tube can be employed. The former has the advantage of aroiding the necessity of forcing the mouth open and using the gag, which often is the most difficult part of the whole feeding process, leading to much struggling, and to the risk of injury to the teeth, this last being by no means a small matter. Sometimes when the patient has prepared himself to keep his mouth firmly closed, he is surprised to find the tabe introduced by the nose and passed into the stomach almost before he realizes what is being done. This is a very decided advantage, but I believe that all the other points are in favour of the mouth tube. From its small size the nasal tube is more likely to enter the glottis, or impinge in some way on the larynx; it is much more difficult for the operator to assure himself that the tube has really passed down the cosophagus towards the stomach; and the introduction of the food through it is necessarily rather slow. On the other hand, from its large size it is almost impossible for the mouth tube to enter the larynx without at once setting up the signs of its wrong position; if it is not swallowed, it is more likely to curve round in the pharynx and show itself again in the back of the throat or in the mouth; the peculiar feeling of its being grasped and drawn on by the muscular fibres of the cesophagus is soon recognized by the operator, and indicates to him that the tube has passed properly; the introduction of the food is more quickly effected; and it allows of a greater range of consistence in the food used-a point of great importance if the feeding has to be continued for some weeks or months. In one case, where the patient was powerful and rery resistive, with a complete set of teeth, making the introduction of the gag impossible without a very serious struggle, I used the nose tabe with success on one occasion; but on a second trial I found that the patient was able to divert its lower end into his mouth, and that the tube was being coiled up 
in the mouth instead of passing on to the stomach. The operator has less control over the nose tube than over the mouth tube, and those patients with whom there is much difficulty in getting the month opened are often the very cases that are able to resist successfully the passage of the nasal tube. From these considerations it seems to me that in the great majority of cases the mouth tube will be found the more suitable and the more convenient for use, but when for any reason the employment of the mouth gag is undesirable, it may with advantage be replaced by the nose tube.

In passing the tube through the mouth, it may be necessary to depress the tongue by means of the finger, but after the tube has reached the lower part of the pharynx the pressure on the tongue should not be continued, as swallowing is more easily effected when the tongue is raised to the roof of the mouth, that being in fact the first movement in the process of ordinary deglutition. Generally the patient makes the swallowing movement very soon after the tube has reached the lower end of the pharynx, but if he does not do so, it may occasionally be helpful to pour a few drops of liquid into the tube. This runs out from the lower end of the tube into the pharynx, below the glottis, and trickling down into the cosophagus sets up the action of swallowing; but in resorting to this expedient, (which indeed is seldom necessary), care must be taken to pour in the liquid slowly, cautiously, and in very small amount, lest it should be forced back into the larynx.

When the tube has been passed, the simplest and best way of introducing the food is by gravitation. For this purpose the vessel containing the food is attached in any suitable way to the upper end of the tube, and raised to a convenient height, the food then running down into the stomach by its own weight. Or a funnel may be fixed on the upper end of the tube, and the food poured into it from a basin or jug. If we wish to aroid any splashing of the food from regurgitation through the tube, the funnel may be fitted with a cover, or we may use the bottle designed for this purpose by Dr. Yellowlees. So far as mere feeding is concerned, the old form of stomach pump is cumbrous, complicated, and difficult to keep clean, and its use gives no special advantage, unless for any reason it is necessary to introduce the food into the stomach very rapidly, and have the process of feeding completed as quickly as possible. 
(3.) Kind of Food used.-When the feeding is occasiunal, or required only for a limited time, milk, custard, or beeftea is generally used. If it needs to be kept up for a long period, the diet should be varied from time to time, and for this purpose eggs, pounded meat (chicken, beef, or inutton), pounded biscuit, gruel, sugar, vegetables, etc., may be used in various combinations, with wine or other stimulants. Tonic or other medicines can be mixed with the food, or administered separately through the tube, if desired. As is well known, ordinary beef-tea contains the extractive and stimulant elements, rather than the nutritive constituents of the meat; and the preparation of beef or mutton by pounding, for use in tube feeding in place of the tea, is a laborious and troublesome process when it has to be often repeated. An easy and useful combination is to have fresh beef-tea made in the ordinary way, and to add to it a suitable amount of the dry meat powders (such as Peptonoids) which contain the albuminoid constituents. I have tried this for one meal in the day, with milk or custard (made of milk, eggs, and sugar) for the other diets, and have found that the patients often keep up their weight satisfactorily upon it. The fatty constituents should not be remored from the beef-tea by skimming, as they help to counteract the constipating effect of the milk diet. It is often useful to wash out the stomach with Condy's fluid or other disinfectant before administering the food, particularly in the cases of melancholic stupor, in which gastro-intestinal torpidity and derangement is so frequently a prominent feature.

(4.) Clinical Cases. - I shall refer only very shortly to three cases under treatment in the Fife District Asylum, in which forcible feeding has been used for considerable periods.

(a.) G. S., admitted 29th June, 1880 ; age on admission,

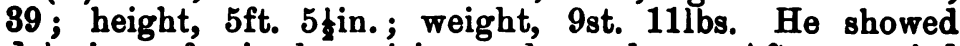
delusions of mixed suspicion and grandeur. After a period of apparent improvement, his delusions became more extravagant. In May, 1884, he refused food altogether ; weight 9st. I slbs. Though fed regularly twice a day with the cesophageal tube, he fell off rapidly to 8st. 4lbs. Three feedings (custards and beef-tea with eggs) were then given each day, and he was kept in bed for a time. On 1st July, 1884, his weight was 7st. 13lbs.; but from that date onwards his bodily condition was on the whole distinctly better, though he still showed considerable fluctuations in weight from 
time to time. In the winter of $1884-85$ one pound of pounded beef was given daily, with regetables, and six ounces of sherry, in addition to custards; and in April, 1885 , this was replaced by beef peptonoids given in freshly made beef-tea, as above mentioned. He has continued to require feeding up to the present time. Occasionally he asks for and eats fruit and sweetmeats, and he has taken biscuits, etc., from his relatives when they visit him, but he resolutely declines to take the ordinary daily food. When questioned about the reason of his conduct, he asserts that he is God and needs nothing to support him, or, patting his mouth with his hand and making the movement of swallowing, says that he has already got the food he wants in his own special way. During the last ten years his weight has sometimes fallen to about $8 \frac{1}{2}$ st., but generally it has been over 9st. In the present year it has ranged from 10st. 21 bs. to 9st. 7lbs., the latter being his weight just now. His highest weight was 10st. 6lbs., noted in the summer of 1894. At that time he was much more active than usual, occupying himself in fishing, and spending the greatest part of the day in the open air, with evident advantage to his bodily health. At present he is less energetic, walking a good deal, and taking an active part in dancing and other amusements, but refusing to engage in any regular work. $\mathrm{He}$ is thin and rather pale, but otherwise in excellent bodily health. The tube has been used in his case over 12,000 times, and he seems likely to need it for some time to come.

(b.) J. H., admitted 19th March, 1888, age 43; height, 5ft. 7 tin.; weight, 9st. 12lbs. He had previously been twice under care in the asylum, and in a previous attack had mutilated himself by chopping off his left forearm just below the elbow. On his last admission he was in a state of acute melancholia, with delusions (e.g., that he was unfit to live) and strong suicidal tendency. On the night before he was sent to the asylum he had made a cut in his arm with the intention of bleeding himself to death. From time to time he refused food, and it was necessary to use forcible feeding several times in November, 1888, again in November, 1889 , and continuously from June, 1890, to June, 1891 . From the latter date he took food voluntarily until December, 1891, when he once more refused it, and he has been fed regularly from that time up to the present. The lowest weight recorded in his case was 9st. 6lbs. in 1892, but generally his weight has ranged from 10st. to 11st., and at 
present is 10st. 2lbs. Unlike G. S., he is very moody and self-absorbed, seldom speaking unless first spoken to, and shows no interest in anything around him. If left to himself, he would sit passive all day, and he practically undertakes no exertion except in regular and compulsory walking exercise.

(c.) H. J., admitted 9th August, 1894, age 35 ; height, 5ft. $4 \frac{1}{2}$ in. ; weight, 11 st. 2 lbs. He is congenitally defective in mind, with much maniacal excitement. He never altogether refused food for any length of time, but took it in insufficient quantity. In November he lost weight rapidly, and suffered from boils and whitlow. The maniacal excitement still continued. In February, 1895, he was fed occasionally with the tube; afterwards he was fed twice daily, but he lost flesh until in April his weight was 8st. 11lbs. The tube feedings were, therefore, increased to three each day, in addition to the food taken voluntarily, and he now weighs 9 st. 5 lbs.

In these three cases prolonged feeding by the soft cesophageal (mouth) tube has produced no complication, and has been of great value in promoting health.

\section{Discussion on Dr. Turnbult' Paper.}

Dr. Briscor said that he had formerly a good deal of experience in artificial feeding, having had several cases of gastrostomy under his care. As the result of later asylum experience he disagreed with the practice of using the nasal tube. It was a most obnoxious proceeding, to which he did not think any one of them would personally submit. He referred to a case invariably rendered sick and uncomfortable by that procedure, and contended that the use of the cosophageal tube was, in the hands of a careful person, a very simple operation. As for the gag, he had found that nothing was better than the finger, or the ordinary dental gag. Of course he took care properly to protect the finger. It was necessary to have plenty of assistants, and the patient ought to be fed sitting up. The apparatus consisted of an india-rubber tube, a common funnel, and a jug. In his experience the only satisfactory method of forcible feeding was by means of the cesophageal tube. He entirely ignored the catheter; he would not allow it to be used on himself, and would not use it on a patient.

Dr. Drapes said that he would much prefer to have a nasal tube used on himself than to have a large tube passed down his oesophagus. He had used the nasal tube much more than the other. One point the last speaker had ignored was the matter of resistance. If a preliminary struggle has to be got over, it exhausts both the patient and the operatior, in which case the nasal tube would have a manifest advantage. As to the danger of the nasal tube entering the larynx, there was a point to be noted which was not much referred to in books, namely, that when the tube had just cleared the palate, by bending the patieut's head on his chest, the tube was enabled to pass on easily to the stomach. Even if the tube did enter the larynx, that mere fact was not of much consequence, as the results of intubation showed; but they must of course be certain that had not occurred when they proceeded to pour in the food. The principles to be followed were extension and immobility, and the patient should be put on his back.

Dr. Crodston expressed his surprise that Dr. Turnbull should have recom. mended the cosophageal in preference to the nasal tube. He himself had dis- 
carded the old gum-elastic tube for the soft cosophageal tube, and found it more suitable, but there was sometimes extraordinary difficulty in opening the mouth. He thought those of them who had had large experience would be very sorry to use a gag in every case. After careful trial of the various methods he now nsed the nose tube, the long catheter-like tube, and since then his faith in it had never deviated. In only two cases at Morniugside had there been difficulty-one in which the nasal aperture was contracted, another in which there was obstruction in getting the instrument down through the pharynx. An important practical point to be attended to was that, after the nose tube had been passed, a teaspoonful of water should be poured down before introducing the food, lest the tube had passed into the larynx. He had never seen a patient the worse for this. At the end of the feeding. in order to clear out the tube so that there should be no drop of fluid which might pass down to the larynx and so cause pneumonia, the same precaution should be adopted.

Dr. MACDONald stated that during his fifteen years of asylum experience he had never used anything but the cosophageal tube in forcible feeding, and he did not intend to use anything else, having never once failed to pass it.

Dr. MERsce asked what means Dr. Clouston adopted for feeding the patient when he failed with the nasal tube. For his own part he never had the slightest difficulty and had never failed to pass the csophageal tube. He thought that the natural way of feeding through the mouth should be followed if possible.

Dr. Clouston said he always kept an œesophageal tube in case of emergency.

Dr. G. M. Robertson had used the cesophageal tube as well as the nasal tube, and had been able to weigh their comparative merits. There were cases in which considerable difficulty was experienced in inserting the gag; sometimes the patient struggled so much and bit so hard that the jaw was injured; he had even known cases where the teeth had been driven into the cavity above the jaw. The nasal tube, he thought, should be emplosed to avoid such results. As a general rule, he used the csophageal tube, which permitted of the administration of semisolid material such as the nasal tube would not pass. It had been said that the passage of the nasal tube was unpleasant; he had passed it on himself and had not found it so, and he thought that there was less disturbance in the case of the nasal tube than of the oesophageal. It was a most dangerous thing to pass a catheter which only reached as far as the soft palate and let the custard drip over the larynx. A nasal tube, much longer and larger than the catheter, was what should be used, so that it might be able to reach half-way down to the stomach. It would sometimes be found impossible to introduce it by one nostril, while it passed readily by the other. Some patients, too, became exceedingly expert in putting the tongue at the back of the throat and pushing the tube forward. But even if the tube did pass into the larynx, it had simply to be drawn out again and passed the right way. Ordinarily, the cesophageal tube was the easier and quicker instrument to pass.

Dr. YkLLOWLkKs agreed with Dr. Turnbull's paper, and decidedly preferred feeding by the month for the reasons Dr. Turnbull had given. In certain cases feeding by the nose might be preferable, but there was no principle involved, and each person must use the method be found most satisfactory. He well remembered when Dr. Clouston condemned nose feeding as earnestly as he now approved it.

Dr. UROURART said a good many of them had been through that discussion before, and they had come no nearer agreement than before. He did not rise to object to what Dr. Turnbull had said, but to ask whether they did not feed their patients forcibly too often ? Prof. Meyer, of Göttingen, had abandoned the practice for a quarter of a century. A good many hundred patients had passed through his hands during that time, and his results were very striking.* He had a horror of feeding patients with the tube on account of unfortunate sequelæ, such as pnenmonias, occurring after the operation, which was not so free from danger, he (Dr. Urquhart) thought, as some people seemed to suppose. He might, there-

"Bee " Journal of Mental Bcience," April, 1895, p. 276. 
fore, be allowed to ask the question whether they could not do with less of forcible feeding in asylums P If they had to use it, a little fluid nourishment poured into the nose and allowed to drop over the palate (as Dr. Morel demonstrated not very long ago in this country) had sometimes a most excellent effect in inducing patients to take food voluntarily.

Dr. Cooke asked whether any member present had experience in feeding with the cosophageal tube passed down only one-third of the length of the cesophagns, and 80 allowing the involuntary fibres to do the rest of the work ? A short time ago they had an accident at Worcester, the patient regurgitating a good deal of the food administered. Syncope had occurred, followed by acute codema of the lungs, and death an hour and a half afterwards. He had asked the senior surgeon of the Worcester Infirmary to be present at the post-murtem examination, as he was strongly of opinion that the method was a very desirable one, and was informed by him that at the Worcester Infirmary they never fed in any other way than by passing the tube one-third down the cesophagus.

Dr. Bkrscos, in reply to this, said he never passed the tube further down the cosophapus than abont seven or eight inches. Considering that the narrowest part of the gullet was at the upper end and the largest calibre at the lower, he did not think that they needed to pass the tube further than that. By the nasal process, if the patient had to be fed every three hours, half-an-hour was consumed, whereas he could feed a patient in five minutes with the ordinary tube.

Dr. CarLtre Johrstong said he had employed the gum elastic tube, the stomachpump, the large oesophageal tube, and the nasal tube. The nasal tube seemed to him to be safer and simpler, and it involved less of a struggle in the process of feeding. He did not happen to find a nasal tube in the surgery when he went to the Melrose Asylum, and had fed with the œsophageal tube, when necessary, ever since. He had never failed either with the nasal or the csophageal tube. The mere question of the particular instrument to be used was, however, very small in comparison with the question whether they should feed with any instrument. He bad now comparatively few cases which really required feeding; hut, besides that, he had, perhaps, grown a little more reluctant to feed than previously, and be did not think that any of his patients had been sufferers owing to that change of practice. At the same time, the tube ought to be used in certain cases of difficulty, for it was better to resort to the use of the tube, so that they might know that the patient was really being fed and to what amount.

Dr. HAres Newingtun recalled a case in Morningside in which he had to feed an ill-nourished woman who had a tendency to subluxation of the jaw. Whenever her mouth was opened in the usual way this occurred, and the idea of feeding through the nose tube occurred to him. As a matter of experience, there were two points for consideration-first, the necessity for introducing the fond readily. easily, and certainly, and second, the production of moral effect. No doubt the old-fashioned stomach pump or some modification of it was extremely useful, bet the nose tube was preferable in the first instance. It was an alarming process for a patient with tender feelings to be suddenly surrounded and subjected to the nae of the cosophageal tube. But in any case they should be sure the patient got all that was intended for him.

A MExBrR asked if any one present had adopted feeding per rectum as an alternative to feeding by the mouth. He had tried it in one or two cases with most salutary effect.

Dr. OUTTERson Woon remarked that the drift of the discussion proved that what was suitable in one case might not be suitable in another. When they failed to feed by the mouth they had to resort to the nasal method, and vice vered.

Dr. Sermour TUra preferred the coosphageal to the nasal tube, especially if the feeding had to be continued for any lengthened period. In the first place the operation occupied less time, and in the second place a greater $\nabla$ ariety of diet could be given. Instead of feeding solely on milk, regetables and other foods could be added; and that was of the greatest importance in preventing the patients from falling into a condition that was anything but healthy. The 
question had been under discussion years ago, when his father pointed out the defects of the nasal tube.

Dr. A. S. Newivaron referred to the direct method of nasal feeding. He frequently fed by the nose and never used the tube, pouring the food from an ordinary feeding cup down one nostril while the other was kept closed. He had seen this done for the first time at Bethlem Hospital, when a clinical student, in the case of a patient who struggled so violently that they conld not open his mouth without breaking his teeth. The result was that the patient soon ceased to resist.

Dr. Graysaaw, as a physician in general practice, approved the method recommended by the last speaker. It had been his lot to feed many patients in that way, and he found that the moral effect was much greater than when the tube was used.

Dr. Soutar said the discussion made one wonder that so much could be said against the different methods which they had individually long ago accepted as their routine practice. He considered that it was a matter of individual experience. He had formerly used the stomach pump and the cesophageal tube, now he employed only the nose tube, and it seemed to him that he had advanced from bad to better in that respect. He had again and again been assured by patients who had experienced both methods that they preferred the nose tube. It was the easier, the simpler, and the more comfortable. He did not think that they had any right to use any means of compelling, as the result of pain or discomfort, the patient to abandon his refusal of food. It was their business to continue the administration of the food in the way most comfortable to him, as well as most efficient. He believed, too, that they did not, as a rule, resort soon enough to forcible feeding. He did not at all agree with those who put off until, as the result of his refusal of food, the patient had become debilitated. Very often the patient would take sufficient to keep himself going, but not sufficient to effect recovery, and they ought, therefore, to treat by forcible feeding long before complete refusal. The dangers, in his opinion, were very much over-estimated. The precaution mentioned by Dr. Clouston of pouring a few drops of water down the tube before giving the food was always used at Barnwood House. On two occasions he had found its value. In one recent case the patient had an extraordinary power of regurgitating her food, and was actually dying of starvation although fed four times a day. A drachm and a half of paraldehyde was given three times a day to overcome this difficulty. The patient fell asleep in a few minutes and was then fed satisfactorily.

The President said that he had never fed patients in any other way than by the mouth,'and had never any difficulty or any bad result. His experience of these cases was not extensive, and he was disposed to continue his present practice till he found reason for departing from it. It was satisfactory to know that, if one method failed, others were available. With regard to Dr. Urquhart's statement of Prof. Meyer's practice, it seemed inconceivable that during a long experience in a large asylum there should never be a case where feeding was necessary.

Dr. Turnbule, in his reply, said that he would not prolong the discussion by referring to the various points which had been raised, but he must make an exception of the statement that any form of feeding was safe. Those members of the Association who were content with pouring food through the nose to the back of the pharynx of a resistive case seemed to him to be following a dangerous practice. He had seen serious results. He would further state that he had purposely limited his remarks to exclude the question as to how often they should resort to forcible feeding, but he might state his opinion that, considering the comparatively slight risk entailed, it should be oftener resorted to than is customary for the sake of the patient. 